\title{
Article \\ Clinical Experience, Knowledge, Attitudes and Practice of Turkish Pediatric Dentists during the COVID-19 Pandemic
}

\author{
Yelda Koç ${ }^{1}$, Serap Akyüz ${ }^{2}$ and Damla Akşit-Bıçak ${ }^{1, * \mathbb{D}}$ \\ 1 Department of Pediatric Dentistry, Faculty of Dentistry, Near East University, Nicosia/TRNC, \\ Mersin 10 99138, Turkey; kocyelda1994@gmail.com \\ 2 Department of Pediatric Dentistry, Faculty of Dentistry, Marmara University, İstanbul 34854, Turkey; \\ sakyuz@marmara.edu.tr \\ * Correspondence: damlaaksit@gmail.com
}

Citation: Koç, Y.; Akyüz, S.;

Akşit-Bıçak, D. Clinical Experience,

Knowledge, Attitudes and Practice of

Turkish Pediatric Dentists during the COVID-19 Pandemic. Medicina 2021,

57, 1140. https://doi.org/10.3390/

medicina57111140

Academic Editors: Cesare D'Amico and Pier Paolo Poli

Received: 7 September 2021

Accepted: 15 October 2021

Published: 21 October 2021

Publisher's Note: MDPI stays neutral with regard to jurisdictional claims in published maps and institutional affiliations.

Copyright: (c) 2021 by the authors. Licensee MDPI, Basel, Switzerland. This article is an open access article distributed under the terms and conditions of the Creative Commons Attribution (CC BY) license (https:/ / creativecommons.org/licenses/by/ $4.0 /)$.

\begin{abstract}
Background and Objectives: "Coronavirus Disease 2019" (COVID-19) is a critical public health problem that has affected all fields, including dentistry. The dental management of children has become even more difficult during the COVID-19 pandemic. The purpose of this study was to evaluate the current knowledge, attitudes and practices of Turkish pediatric dentists who have been providing dental treatments to children during the COVID-19 pandemic. Materials and Methods: After receiving ethical approval, this cross-sectional study was conducted using the Google Forms online survey instrument. An online questionnaire link was sent to all the members of the Turkish Society of Paediatric Dentistry by e-mail and through social media. Statistical analyses were performed using descriptive statistics and Chi-square test; a $p$-value less than 0.05 was considered statistically significant. Results: A total of 200 pediatric dentists participated in this study and most of them $(82 \%)$ only performed emergency dental treatments, whereas $18.5 \%$ performed both emergency and routine dental practices during the COVID-19 pandemic. The vast majority $(72.5 \%)$ of pediatric dentists prescribed antibiotics and analgesics to their patients who were not cooperative with nonpharmacological behavior management techniques. The findings of the current study showed that the Turkish pediatric dentists had a good level of knowledge about COVID-19, satisfactorily conducted most of the infection control measures before and after the dental treatments, and attached importance to the use of PPEs; however, infection control measures during the dental treatments could be implemented better. Conclusions: Along with all precautions, the vaccination of healthcare workers and requesting a recent test result from patients showing a lack of COVID-19 disease before dental appointments could be used as effective infection control measures. Additionally, pediatric dentists should continue to follow local and universal guidelines, and education programmes should be frequently implemented in order to keep their COVID-19 management strategies up to date.
\end{abstract}

Keywords: anxiety; behavior management; children; coronavirus; COVID-19; infection control; oral health; pediatric dentistry; personal protective equipment; questionnaire

\section{Introduction}

"Coronavirus Disease 2019" (COVID-19) became a critical public health problem after it was first detected in Wuhan, China towards the end of December 2019; the International Committee on Taxonomy of Viruses subsequently reported the name of the new coronavirus responsible for the disease to be SARS-CoV-2. From the beginning of the pandemic, despite all the measures taken to control viral spread, COVID-19 cases emerged worldwide, which indicates that the pandemic has yet to be effectively controlled [1,2]. The SARS-CoV-2 virus is known to be highly contagious, and the possible transmission routes include direct transmission with respiratory droplets through coughing and sneezing, contact with saliva, eye and blood, airborne transmission, indirect transmission via contact with fomites, and fecal-oral transmission [3]. In terms of the risk of COVID-19 exposure, healthcare workers 
who are constantly in physical contact with patients are among the risk groups. Dentists are recognized to be the highest-risk group among healthcare workers because the required distance for prevention is unobtainable during dental practices, and there is an increased risk of contamination with SARS-CoV-2 through the aerosols and droplets created while performing clinical procedures $[1,4,5]$. Thus, in order to control viral spread, daily dental practices were reduced/stopped in regions where COVID-19 was widespread, and only emergent/urgent cases were treated [2].

Although COVID-19 vaccinations have been started around the world, widespread immunization requires time and dental professionals are still at high risk of cross infection [5]. Furthermore, pre-symptomatic and asymptomatic patients are both primary sources of SARS-CoV-2 transmission, because at the time of contact, they display no warning signs or symptoms [6]. Pediatric dentists are at higher risk due to the fact that children present nonspecific/mild symptoms, or they could be asymptomatic. Therefore, all child patients and parents should be regarded as potential carriers of COVID- 19 unless confirmed otherwise [7]. Standard infection control procedures applied in daily clinical routines will not be as effective and sufficient for proper protection during the COVID-19 era. The World Health Organization (WHO), the American Dental Association (ADA) and The Centers for Disease Control and Prevention (CDC) recommend that dental practices and hospitals implement rigid and effective infection control protocols to ensure that dentists and dental staff prevent the spread of COVID-19. It is important to prevent the spread of the infectious disease with the precautions applied before the patient comes to the clinic, in the waiting room, during and after the treatment in line with the protocols that dental health personnel must adopt [8]. The WHO has defined this pandemic, of which countries will be at different stages at different times, as having six distinct phases. The planning and treatment options applied in the acute phase of the COVID-19 pandemic may change in the later stages. Therefore, it is difficult to give universal guidelines, which means that it is important to comply with local updated guidelines [7]. At the beginning of the COVID-19 pandemic, the Turkish Association of Paediatric dentistry responded quickly and published guidelines in the Turkish language in order to raise the knowledge and awareness of pediatric dentists in Turkey. Dental teams must follow the instructions and guidelines for better and safer practice during the COVID-19 pandemic [8-10].

According to all this information, the purpose of this study was to evaluate the current knowledge, attitudes and practices of Turkish pediatric dentists who have been providing dental treatments during the COVID-19 pandemic, and to compare and interpret the findings with other studies. The hypothesis of this study was that Turkish pediatric dentists have sufficient knowledge, attitudes and practices about COVID-19. It is predicted that the COVID-19 pandemic will ultimately end like the ones before, but the procedures applied/not applied and experiences evaluated will provide valuable learning for future possible epidemics. Additionally, this study aims to share and transfer the experiences, opinions and needs of Turkish pediatric dentists with other pediatric dentists during the pandemic period, and can therefore be considered as a guiding study in this field.

\section{Materials and Methods}

Ethical approval for this cross-sectional study was obtained from the Research Ethics Committee of Near East University (YDU/2020/79-1083). The study was conducted using the Google Forms (Google LLC, Menlo Park, CA, USA) online survey instrument. The sampling frame for this study comprised pediatric dentistry specialists and postgraduate students in pediatric dentistry who worked at a state university hospital, state clinic/center/hospital, private university hospital, or private practice/clinic/hospital in Turkey and the Turkish Republic of Northern Cyprus. The self-administered questionnaire prepared in Turkish was firstly piloted on 20 colleagues in order to ensure its clarity and feasibility. The English language version of the questionnaire can be found in Supplementary File S1 (See Supplementary Materials). After making minor changes, the questionnaire was deemed to be comprehensible and no other corrections were required. First of all, the 
online questionnaire link was sent to all the members of the Turkish Society of Paediatric Dentistry by e-mail. In addition, pediatric dentists were invited to participate via the Facebook groups of Turkish pediatric dentists as well as WhatsApp. Attempts were made to reach all pediatric dentists working in all cities across the country. Participation in the study was voluntary and identification information was not collected from the participants. Information about the study was included in the form and the participants provided their consent to participate before observing the content of the questionnaire. Thus, participants participated voluntarily in the study. The data collection was performed from June 2020 to September 2020. The questionnaire consists of 40 questions divided into 5 parts in order to assess the knowledge, attitude and practice of Turkish pediatric dentists during the COVID-19 pandemic. The first part of the questionnaire consists of demographic data including the region, gender, age, years of practice, education status and institution of participants. In addition, this part includes questions related to the participants' working experience during the COVID-19 pandemic. The second part of the questionnaire includes questions aimed at assessing the knowledge of the pediatric dentists related to the COVID19 pandemic. The third part includes the attitudes of participants when encountering a child patient or parent who had signs or symptoms of acute respiratory tract infection, and attitudes towards personal protective equipment (PPE) usage. The fourth part includes emergency situations encountered by participants during the COVID-19 pandemic. The final part includes infection control measures applied before/during/after dental treatments and participants' practice measures when treating non-cooperative children during the COVID-19 pandemic.

\section{Statistical Analysis}

In this study, IBM SPSS-21 software was used for statistical analysis. The mean, standard deviation, frequency and percentage distributions of the variables were found with descriptive statistics. With the Chi-square analysis applied to the categorical variables, we observed whether they had a statistically significant difference. As a result of categorical data analysis, those with a $p$-value less than 0.05 were considered statistically significant and are indicated in the tables.

\section{Results}

A total of 200 pediatric dentists participated in this study. The majority of the participants were from Turkey (96\%), and the remainder were from the Turkish Republic of Northern Cyprus ( $4 \%$ ). Additionally, most of the pediatric dentists were female $(86 \%)$ and only $14 \%$ were male. In total, $47 \%$ of all pediatric dentists were between 20 and 30 years of age, $40 \%$ were $31-40$ years of age, $11.5 \%$ were $41-50$ years of age and only 3 pediatric dentists were 51 years of age or over. In total, $40 \%$ of participants were postgraduate students in pediatric dentistry, whereas $60 \%$ were pediatric dentistry specialists. Approximately $57 \%$ of all pediatric dentists worked in a state institution and $43.5 \%$ in a private institution. Among them, $64 \%$ of the study participants were academicians working in either state or private university hospitals (Table 1 ).

The vast majority of pediatric dentists $(96 \%)$ reported that their working time decreased and $75 \%$ continued to live with their family during the COVID-19 lockdown period. None of the participants had a COVID-19 infection prior to participating in the study. Family members of three of the pediatric dentists had COVID-19 infection. Furthermore, 46 pediatric dentists' colleagues (healthcare workers in the same institution) also had COVID-19 infections. Only four female pediatric dentists worked in the filiation team and $55 \%$ of all participants had attended a webinar on COVID-19 (Table 2). The highest rate of participation in a webinar programmer was found at private university hospitals $(77.4 \%)$ $(p<0.05)$. 
Table 1. Participants' demographic data.

\begin{tabular}{cccc}
\hline & & $\boldsymbol{n}$ & $\mathbf{\%}$ \\
\hline \multirow{2}{*}{ Region } & Turkish Republic of Northern Cyprus & 8 & 4 \\
& Turkey & 192 & 96 \\
\hline \multirow{2}{*}{ Gender } & Male & 28 & 14 \\
& Female & 172 & 86 \\
\hline \multirow{2}{*}{ Age } & $20-30$ & 94 & 47 \\
& $31-40$ & 80 & 40 \\
& $41-50$ & 23 & 11.5 \\
& $51-60$ & 2 & 1 \\
Years of Practice In Pediatric Dentistry & $\geq 60$ & 1 & 0.5 \\
& $0-5$ & 92 & 46 \\
& $6-10$ & 56 & 28 \\
& $11-20$ & 46 & 23 \\
& $21-30$ & 5 & 2.5 \\
Education Status & $\geq 31$ & 1 & 0.5 \\
\hline \multirow{2}{*}{ Institution } & Pediatric Dentistry Specialist & 120 & 60 \\
& Postgraduate student in Pediatric Dentistry & 80 & 40 \\
\hline & State University Hospital & 97 & 48.5 \\
& State Clinic/Center/Hospital & 16 & 8 \\
& Private University Hospital & 31 & 15.5 \\
& Private Practice/Clinic/Hospital & 56 & 28 \\
\hline
\end{tabular}

Table 2. Participants' working experience during the COVID-19 pandemic period.

\begin{tabular}{ccc}
\hline Questions & Yes $(n / \%)$ & No (n/\%) \\
\hline $\begin{array}{c}\text { Did you continue to live with your family while working } \\
\text { during the COVID-19 lockdown period? }\end{array}$ & $150(75)$ & $50(25)$ \\
\hline Have you had COVID-19 infection? & 0 & $190(100)$ \\
\hline $\begin{array}{c}\text { Have any of your family members had a COVID-19 infection? } \\
\text { Have any dentists and healthcare personnel working in your } \\
\text { institution had a COVID-19 infection? }\end{array}$ & $3(1.5)$ & $16(23)$ \\
\hline $\begin{array}{c}\text { Have you attended a webinar on COVID-19? } \\
\text { Have you worked in the filiation team? }\end{array}$ & $110(55)$ & $90(45)$ \\
\hline Did your working time decrease during this period? & $4(2)$ & $196(98)$ \\
\hline
\end{tabular}

When pediatric dentists were asked about the symptoms of COVID-19, almost all of them knew the main symptoms, such as fever $(99.5 \%)$, shortness of breath $(98 \%)$ and dry cough $(97 \%)$. Approximately $90 \%$ of all participants knew about asymptomatic infection joint or muscle pain $(82.5 \%)$ and sore throat $(79 \%)$. The least known symptoms were diarrhea $(66.5 \%)$, sore eyes $(51 \%)$, vomiting $(46.5 \%)$, runny nose $(37.5 \%)$ and skin rash (35\%). Only $29.5 \%$ of all participants reported all of these as symptoms of COVID-19. Furthermore, pediatric dentists were asked about the transmission routes of COVID-19. All pediatric dentists knew about direct transmission via respiratory droplets through coughing and sneezing. Some participants listed contact with saliva (94\%), indirect transmission through contact with fomites (89.5\%), airborne transmission (87.5\%) and contact with the eye $(85 \%)$. The least known transmission routes were fecal-oral transmission $(58 \%)$ and blood (53.5\%) (Table 3). 
Table 3. Knowledge of participants related to symptoms and transmission routes of COVID-19.

\begin{tabular}{|c|c|c|}
\hline & & $n(\%)$ \\
\hline \multirow{12}{*}{ Symptoms } & Fever & $199(99.5)$ \\
\hline & Dry cough & $194(97.0)$ \\
\hline & Shortness of breath & $196(98.0)$ \\
\hline & Diarrhea & $133(66.5)$ \\
\hline & Vomiting & $93(46.5)$ \\
\hline & Runny nose & $75(37.5)$ \\
\hline & Sore throat & $158(79.0)$ \\
\hline & Sore eyes & $102(51.0)$ \\
\hline & Skin Rash & $70(35.0)$ \\
\hline & Joint or muscle pain & $165(82.5)$ \\
\hline & Without Symptoms & $181(90.5)$ \\
\hline & All of them & $59(29.5)$ \\
\hline \multirow{7}{*}{ Transmission Routes } & Direct transmission through: Coughing, sneezing & $200(100)$ \\
\hline & Saliva & $188(94.0)$ \\
\hline & Eye & $170(85)$ \\
\hline & Blood & $107(53.5)$ \\
\hline & Fecal-oral transmission & $116(58)$ \\
\hline & Airborne transmission & $175(87.5)$ \\
\hline & Indirect transmission through contact with fomites & $179(89.5)$ \\
\hline
\end{tabular}

All pediatric dentists stated that information such as "Dental Healthcare workers are at high risk of being infected with COVID-19 when compared with the general population," and "Aerosol and droplets formed during dental treatment, increase the risk of spread and transmission of COVID-19" were true. Regarding other statements, the vast majority of pediatric dentists said that the information was true, as shown in Table 4. However, $75 \%$ of participants said that the statement "Virus detection from saliva samples can be a diagnostic method" was true, and $57.5 \%$ of participants acknowledged that the statement "Protection with mask is not recommended for children under 2 years of age and children unable to remove mask without assistance" was true (Table 4).

Common infection control practices used in the participants' institutions before dental treatment included "establishing pre-control staff at the institution for screening the temperature with non-contact thermometer and checking appropriate use of face masks" $(86.4 \%)$, "posting signs and posters at the entrance of the waiting room and in the areas visible to patients to provide instructions about social distance, hand hygiene and respiratory hygiene measures" (81.8\%) and "in the waiting room, applying social distance rules, and asking some of the patients to wait outside the building if necessary" (81.3\%) respectively. Approximately $70 \%$ of the participants obtained medical and dental anamnesis from pediatric patients and parents. Other infection control measures were used at rates varying between 70 and $80 \%$. Approximately $57 \%$ of participants reported removing toys or reading materials that could be touched by other children in their institutions. All infection control measures used in the institutions of participants before dental treatment are shown in Table 5. 
Table 4. Knowledge of participants related to the statements about COVID-19.

\begin{tabular}{|c|c|c|c|}
\hline Statement & Answer & & \\
\hline & True & False & I Don't Know \\
\hline $\begin{array}{l}\text { Dental Healthcare workers are at high risk of being infected with } \\
\text { COVID-19 when compared with the general population. }\end{array}$ & $200(100.0)$ & $0(0.0)$ & $0(0.0)$ \\
\hline $\begin{array}{l}\text { A single negative PCR test result does not exclude the possibility of } \\
\text { COVID-19 infection among suspected patients. }\end{array}$ & $195(97.5)$ & $3(1.5)$ & $2(1.0)$ \\
\hline $\begin{array}{l}\text { Aerosol and droplets formed during dental treatment increase the risk of } \\
\text { spread and transmission of COVID-19. }\end{array}$ & $200(100.0)$ & $0(0.0)$ & $0(0.0)$ \\
\hline $\begin{array}{l}\text { Pediatric patients present additional risks of transmission due to the use } \\
\text { of appliances, difficulty in using personal protective equipment, and } \\
\text { coming to the clinic with one or more parents. }\end{array}$ & $197(98.5)$ & $3(1.5)$ & $0(0.0)$ \\
\hline Children can be asymptomatic or present mild, non-specific symptoms. & $191(95.5)$ & $4(2.0)$ & $5(2.5)$ \\
\hline $\begin{array}{l}\text { Asymptomatic patients and pre-symptomatic patients in the incubation } \\
\text { period could be carriers of COVID-19. }\end{array}$ & $198(99.0)$ & $0(0.0)$ & $2(1.0)$ \\
\hline $\begin{array}{l}\text { All child patients and parents should be considered as potential carriers } \\
\text { of COVID-19 unless proved otherwise. }\end{array}$ & $194(97.0)$ & $5(2.5)$ & $1(0.5)$ \\
\hline Virus detection from saliva samples can be a diagnostic method. & $150(75.0)$ & $11(5.5)$ & 39 (19.5) \\
\hline $\begin{array}{l}\text { Protection with mask is not recommended for children under } 2 \text { years of } \\
\text { age and children unable to remove mask without assistance }\end{array}$ & 115 (57.5) & 27 (13.5) & $58(29.0)$ \\
\hline
\end{tabular}

Table 5. Infection control practices used in institutions of participants before dental treatment.

\begin{tabular}{lcc}
\hline & $n$ & (\%) \\
\hline $\begin{array}{l}\text { Posting visual public notices for all visitors to the building entrances including signs and symptoms } \\
\text { of COVID-19 and warning not to enter into the facility if they are exhibiting any of these symptoms. }\end{array}$ & 156 & 78.8 \\
\hline $\begin{array}{l}\text { Triaging dental patients by phone or online conferencing in order to decide the urgency of dental } \\
\text { condition and COVID-19 risk status of patients. }\end{array}$ & 120 & 60 \\
\hline $\begin{array}{l}\text { Establishing pre-control staff at the institution for screening the temperature with a non-contact } \\
\text { thermometer and checking appropriate use of face masks. }\end{array}$ & 171 \\
\hline Questioning the travel history and presence of symptoms of everyone before entering the building. & 143 & 141 \\
\hline $\begin{array}{l}\text { Taking medical and dental anamnesis from pediatric patients and parents. } \\
\text { Placing hand sanitizer and asking children and parents to use it while entering the clinic. }\end{array}$ & 145 \\
\hline $\begin{array}{l}\text { Posting signs and posters at the entrance of the waiting room and in the areas visible to patients to } \\
\text { provide instructions about social distancing, hand hygiene and respiratory hygiene measures. }\end{array}$ & 162 \\
\hline $\begin{array}{l}\text { Scheduling appointments of patients at times not close to each other in order to prevent crowding } \\
\text { and establishment of the time required for disinfection and ventilation. }\end{array}$ & 142 & 73.2 \\
\hline $\begin{array}{l}\text { In the waiting room, applying social distance rules, and asking some of the patients to wait outside } \\
\text { the building if necessary. }\end{array}$ & 161 \\
\hline $\begin{array}{l}\text { Ensuring that the pediatric patient comes to the clinic with a single accompanying person. } \\
\text { Removing toys or reading materials that could be touched by other children. }\end{array}$ & 135 \\
\hline
\end{tabular}

Forty-four pediatric dentists reported that they had encountered a child patient or parent who had signs and symptoms of acute respiratory infection. Among them, $14(31.8 \%)$ pediatric dentists referred these patients to hospital after treating the patient, $28(63.6 \%)$ referred the patients to the hospital with a medical mask without conducting the treatment and $2(4.5 \%)$ refused to treat the patients and asked them to leave the clinic. On the other hand, 156 pediatric dentists reported that they had not encountered a child patient or parent who had signs and symptoms of acute respiratory infection. However, if they 
were faced with such a situation, $24(15.4 \%)$ pediatric dentists said they would refer these patients to hospital after treating the patient, $110(70.5 \%)$ said they would refer the patient to a hospital with a medical mask without conducting the treatment, and $22(14.1 \%)$ would refuse to treat the patient and would ask them to leave the clinic (Table 6) $(p<0.05)$.

When the pediatric dentists were asked about the dental procedures they practiced during the COVID-19 pandemic, the vast majority $(82 \%)$ said they only performed emergency dental treatments, whereas $37(18.5 \%)$ performed both emergency and routine dental practices. The most common emergency situations were reported as severe pain caused by pulpal inflammation $(94 \%)$, abscess or bacterial infection causing localized pain and extraoral swelling (86.5\%), luxations, dental avulsions (41\%), dental fractures causing pain or soft tissue injuries caused by trauma $(35.5 \%)$, and the aerosol-free treatment of temporary restoration loss/fractures $(27 \%)$, respectively. Other emergency situations are also presented in Table 7.

Table 6. Attitudes of participants when faced with a child patient or parent who had signs and symptoms of acute respiratory infection.

\begin{tabular}{|c|c|c|c|c|c|c|}
\hline & \multicolumn{5}{|c|}{ What Would Your Attitude Be in Such a Situation? } & \multirow[b]{2}{*}{$p$} \\
\hline & & $\begin{array}{l}\text { I Refer Them to the } \\
\text { Hospital after Treating } \\
\text { the Patient }(n / \%)\end{array}$ & $\begin{array}{l}\text { I Refer the Patient to the } \\
\text { Hospital with Medical } \\
\text { Mask without Conducting } \\
\text { Treatment }(n / \%)\end{array}$ & $\begin{array}{l}\text { I Refuse to Treat the } \\
\text { Patient and Ask } \\
\text { Them to Leave the } \\
\text { Clinic }(n / \%)\end{array}$ & $\begin{array}{l}\text { Total } \\
(n / \%)\end{array}$ & \\
\hline \multirow{2}{*}{$\begin{array}{l}\text { Have you encountered a child patient or } \\
\text { parent who had signs and symptoms of } \\
\text { acute respiratory infection? }\end{array}$} & Yes & $14(31.8)$ & $28(63.6)$ & $2(4.5)$ & $44(100)$ & \multirow{2}{*}{0.021} \\
\hline & No & $24(15.4)$ & $110(70.5)$ & $22(14.1)$ & $156(100)$ & \\
\hline
\end{tabular}

Pearson Chi-square test.

Table 7. Emergency situations encountered by participants during the COVID-19 pandemic period.

\begin{tabular}{|c|c|c|c|}
\hline & & $n$ & $\%$ \\
\hline \multirow{3}{*}{$\begin{array}{c}\text { Dental procedures performed } \\
\text { during the COVID-19 } \\
\text { lockdown period }\end{array}$} & Emergency dental treatments only & 164 & 82 \\
\hline & Routine dental practices & 6 & 3 \\
\hline & Both of them & 37 & 18.5 \\
\hline \multirow{15}{*}{$\begin{array}{l}\text { Emergency dental treatment } \\
\text { performed during the } \\
\text { COVID-19 lockdown period }\end{array}$} & Severe pain caused by pulpal inflammation & 188 & 94 \\
\hline & Pericoronitis, pain in the third molar region & 0 & 0 \\
\hline & Abscess or bacterial infection causing localized pain and extraoral swelling & 173 & 86.5 \\
\hline & Dental fractures causing pain or soft tissue injuries caused by trauma & 71 & 35.5 \\
\hline & Luxations, dental avulsions & 82 & 41 \\
\hline & Acute and painful lesions/ulcerations of the oral mucosa & 39 & 19.5 \\
\hline & $\begin{array}{l}\text { Dental treatments of oncology patients who are scheduled for } \\
\text { organ transplantation }\end{array}$ & 21 & 10.5 \\
\hline & Intraoral/extraoral infections that may compromise the patient's airway & 19 & 9.5 \\
\hline & Dental treatments required before general medical procedures & 18 & 8 \\
\hline & Aerosol-free treatment of temporary restoration loss/fractures & 54 & 27 \\
\hline & Maxillofacial trauma & 17 & 8.5 \\
\hline & $\begin{array}{l}\text { Adjustment of the orthodontic apparatus if it has caused ulceration or pain } \\
\text { on the oral mucosa }\end{array}$ & 41 & 20.5 \\
\hline & Life-threatening or uncontrolled oral tissue bleeding & 6 & 3 \\
\hline & Suture removal & 6 & 3 \\
\hline & Breakage of space maintainer & 1 & 0.5 \\
\hline
\end{tabular}


When the pediatric dentists were asked about PPE usage, scrubs (87\%), surgical masks $(90 \%)$, face shields $(83 \%)$, goggles $(71 \%)$, disposable surgical gowns $(70.5 \%)$, disposable gloves $(92.5 \%)$, and disposable medical caps $(83.5 \%)$ were found to be used widely in both aerosol-generating procedures (AGPs) and non-AGPs. N95 respirators were used only in AGPs by $21 \%$, and used in both AGPs and non-AGPs by $51 \%$. FFP2 respirators were used in only AGPs by $16 \%$, and were used in both AGPs and non-AGPs by $43.5 \%$. Some PPEs were reported to have never been used by participants, such as P100 respirators $(85.5 \%)$, elastomeric half masks $(79 \%)$, FFP3 respirators $(64 \%)$, waterproof shoe covers $(61.5 \%)$ and disposable protective coveralls (58.5\%). All used PPEs are displayed in Table 8.

Table 8. Participants' attitudes towards personal protective equipment (PPE) usage.

\begin{tabular}{|c|c|c|c|c|c|c|}
\hline & \multicolumn{2}{|c|}{$\begin{array}{c}\text { Only in Aerosol- } \\
\text { Generating Procedures }\end{array}$} & \multicolumn{2}{|c|}{$\begin{array}{l}\text { Used in Both Aerosol Generating and } \\
\text { Non-Aerosol Generating Procedures }\end{array}$} & \multicolumn{2}{|c|}{ Never Used } \\
\hline & $n$ & $\%$ & $n$ & $\%$ & $n$ & $\%$ \\
\hline Scrubs & 11 & 5.5 & 174 & 87 & 15 & 7.5 \\
\hline Surgical mask & 14 & 7 & 180 & 90 & 6 & 3.0 \\
\hline N95 respirator & 42 & 21 & 102 & 51 & 56 & 28 \\
\hline P100 respirator & 10 & 5 & 19 & 9.5 & 171 & 85.5 \\
\hline FFP2 respirator & 32 & 16 & 87 & 43.5 & 81 & 40.5 \\
\hline FFP3 respirator & 18 & 9 & 54 & 27 & 128 & 64 \\
\hline Goggles & 26 & 13 & 142 & 71 & 32 & 16 \\
\hline Face shield & 29 & 14.5 & 166 & 83 & 5 & 2.5 \\
\hline Elastomeric half mask & 9 & 4.5 & 33 & 16.5 & 158 & 79 \\
\hline Disposable surgical gown & 25 & 12.5 & 141 & 70.5 & 34 & 17 \\
\hline Disposable protective coverall & 35 & 17.5 & 48 & 24 & 7 & 58.5 \\
\hline Disposable gloves & 14 & 7 & 185 & 92.5 & 1 & 0.5 \\
\hline Disposable medical cap & 23 & 11.5 & 167 & 83.5 & 10 & 5 \\
\hline Waterproof shoe cover & 13 & 6.5 & 64 & 32 & 123 & 61.5 \\
\hline
\end{tabular}

One hundred and seventy-four $(87 \%)$ pediatric dentists thought that their PPE increased the anxiety levels of children. In total, $110(55 \%)$ participants explained their PPE to children by saying that they were wearing an astronaut suit, $52(26 \%)$ said they had become a superhero, 119 (59.5\%) explained the reason, and 43 (21.5\%) said they did not give any explanation. One hundred and sixty-eight $(84 \%)$ participants paid attention to the proper order for donning and doffing their PPE, but only $55 \%$ of the participants paid attention to removing their own and other dental healthcare workers' PPE in a separate isolation room. In total, 102/168 pediatric dentists who paid attention to the proper order for donning and doffing their PPE also paid attention to removing their own and other dental healthcare workers' PPE in a separate isolation room $(p<0.05)$. Approximately $80 \%$ of participants encountered burning, stinging, itching, dryness, etc. on their skin due to frequent hand cleaning and the long-term use of PPE. Furthermore, 141/168 (83.9\%) pediatric dentists who paid attention to the proper order for donning and doffing their PPE also encountered a situation such as burning, stinging, itching or dryness on their skin due to frequent hand cleaning and the long-term use of PPE $(p<0.05)$ (Table 9). 
Table 9. Participants' attitudes related to PPE.

\begin{tabular}{|c|c|c|c|}
\hline & & $n$ & $\%$ \\
\hline \multirow{5}{*}{ How did you explain your personal protective equipment to children? } & I wore an astronaut suit & 110 & 55 \\
\hline & I became a superhero & 52 & 26 \\
\hline & I explained the reason & 119 & 59.5 \\
\hline & $\begin{array}{l}\text { Did not give any } \\
\text { explanation }\end{array}$ & 43 & 21.5 \\
\hline & Other & 4 & 2 \\
\hline \multirow{2}{*}{ Do you think that personal protective equipment increases the anxiety levels of children? } & Yes & 174 & 87.0 \\
\hline & No & 26 & 13.0 \\
\hline \multirow{2}{*}{$\begin{array}{l}\text { Have you paid attention to proper order for donning and doffing your personal protective } \\
\text { equipment? }\end{array}$} & Yes & 168 & 84.0 \\
\hline & No & 32 & 16.0 \\
\hline \multirow{2}{*}{$\begin{array}{l}\text { Have you paid attention to removing your and other dental healthcare workers' protective } \\
\text { equipment in a separate isolation room? }\end{array}$} & Yes & 110 & 55.0 \\
\hline & No & 90 & 45.0 \\
\hline \multirow{2}{*}{$\begin{array}{l}\text { Have you ever encountered a situation such as burning, stinging, itching, dryness on your } \\
\text { skin due to frequent hand cleaning and long-term use of personal protective equipment? }\end{array}$} & Yes & 161 & 80.5 \\
\hline & No & 39 & 19.5 \\
\hline
\end{tabular}

The infection control practices used by the participants during treatment are displayed in Table 10. In total, $62 \%$ of all participants used manual instrumentation, $59.5 \%$ continued to make patients' appointments via phone, WhatsApp and social networks, and $56.5 \%$ treated only one patient in a room. Furthermore, 39\% of all participants did not let the parent into the treatment room, while $35.5 \%$ applied interim therapeutic restorations (ITR), 34.5\% used high-volume saliva ejectors, $33.5 \%$ applied preprocedural oxidative or antimicrobial mouth rinse, $29.5 \%$ used four-handed dentistry, $29 \%$ used an aerosol box and $24.5 \%$ used slow-speed handpieces. Rarely used methods included dental extraoral suction systems $(6.5 \%)$, rubber-dam (6\%), chemomechanical caries removal systems $(4.5 \%)$, two before three after hand hygiene $(4.5 \%)$, and the use of a dental handpiece with antiretraction function $(2.5 \%)$. Only $23.5 \%$ of the participants reported that they used an air water syringe, and 19\% used a high-speed handpiece and ultrasonic instruments (Table 10). When the pediatric dentists were asked about obtaining X-rays from child patients during the COVID-19 pandemic period, 59.5\% stated that they obtained only panoramic radiographs, $24 \%$ obtained both panoramic and intraoral radiographs, $4 \%$ obtained only intraoral radiographs and $12.5 \%$ did not obtain any radiographs (Table 10). Approximately $65 \%$ of pediatric dentists reported that they had pediatric patients who were not cooperative with non-pharmacological behavior management techniques during the COVID-19 lockdown period (Table 10).

When pediatric dentists were asked about their treatment measures applied to children who were not cooperative with non-pharmacological behavior management techniques during the COVID-19 pandemic period, the vast majority (72.5\%) reported that they prescribed antibiotics and analgesics to their pediatric patients. In total, 33\% of participants said they conducted atraumatic restorative treatment (ART), 11.5\% applied general anesthesia and $8 \%$ used physical restraining in order to control children's sudden movements during dental treatment. It was found that the Hall technique, chemomechanical caries removal, sedation applications, laser applications and silver diamine fluoride (SDF) applications were not widely used (Table 11). 
Table 10. Infection control practices used by the participants during treatment.

\begin{tabular}{|c|c|c|c|}
\hline & & $n$ & $\%$ \\
\hline \multirow{17}{*}{$\begin{array}{l}\text { Which measures did you use while treating pediatric patients } \\
\text { during the COVID-19 lockdown? }\end{array}$} & Not letting the parent into the treatment room & 78 & 39.0 \\
\hline & Treatment of only one patient in a room & 113 & 56.5 \\
\hline & Aerosol box & 58 & 29.0 \\
\hline & Rubber dam & 12 & 6.0 \\
\hline & High-speed handpiece and ultrasonic instruments & 38 & 19.0 \\
\hline & Manual instruments, hand instrumentation & 125 & 62.5 \\
\hline & Slow-speed handpieces & 49 & 24.5 \\
\hline & Dental handpiece with anti-retraction function & 5 & 2.5 \\
\hline & Chemomechanical caries removal & 9 & 4.5 \\
\hline & Interim therapeutic restorations & 71 & 35.5 \\
\hline & Four-handed technique & 59 & 29.5 \\
\hline & Air water syringe & 47 & 23.5 \\
\hline & $\begin{array}{l}\text { Preprocedural oxidative or antimicrobial } \\
\text { mouth-rinse }\end{array}$ & 67 & 33.5 \\
\hline & High-volume saliva ejectors & 69 & 34.5 \\
\hline & Dental extraoral suction system & 13 & 6.5 \\
\hline & Providing two before three after hand hygiene & 9 & 4.5 \\
\hline & $\begin{array}{l}\text { Continuing patients' control appointments via } \\
\text { phone, WhatsApp and social networks }\end{array}$ & 119 & 59.5 \\
\hline \multirow{4}{*}{$\begin{array}{l}\text { Have you obtained X-rays from your pediatric patients during the } \\
\text { COVID-19 lockdown? }\end{array}$} & Yes, both intraoral and panoramic radiographs & 48 & 24 \\
\hline & Yes, intraoral radiographs only & 8 & 4 \\
\hline & Yes, only panoramic radiographs & 119 & 59.5 \\
\hline & No & 25 & 12.5 \\
\hline \multirow{2}{*}{$\begin{array}{l}\text { During the COVID-19 lockdown, did you have a pediatric patient } \\
\text { who was not cooperative with non-pharmacological behavior } \\
\text { management techniques? }\end{array}$} & Yes & 129 & 64.5 \\
\hline & No & 71 & 35.5 \\
\hline
\end{tabular}

Table 11. Participants' practice measures used with children who were not cooperative with nonpharmacological behavior management techniques during the COVID-19 pandemic period.

\begin{tabular}{lcc}
\hline & $n$ & $\mathbf{( \% )}$ \\
\hline Use of antibiotics and analgesics & 145 & 72.5 \\
\hline Inhalation sedation & 9 & 4.5 \\
\hline Enteral sedation & 2 & 1.0 \\
\hline Parenteral sedation & 2 & 1.0 \\
\hline General anesthesia & 23 & 11.5 \\
\hline Physical restraining & 16 & 8.0 \\
\hline Atraumatic restorative treatment & 66 & 33.0 \\
\hline Hall technique & 9 & 4.5 \\
\hline Chemomechanical caries removal & 7 & 3.5 \\
\hline Laser applications & 1 & 0.5 \\
\hline Silver diamine fluoride application & 6 & 3.0 \\
\hline None of them & 28 & 14.0 \\
\hline
\end{tabular}

Infection control practices used by the participants after treatment are displayed in Table 12. The infection control measures used were stated as ventilation of the treatment 
room after each patient (85\%), regular disinfection of common areas, door handles, chairs and tables with $0.1 \%$ sodium hypochlorite $(72.5 \%)$, disinfection of reusable PPE with $70 \%$ alcohol after each usage (68\%), disinfection of commonly used areas such as dental unit, dental light, dental X-ray machine after each patient with $70 \%$ ethanol, $0.1 \%$ sodium hypochlorite, or $0.5 \%$ hydrogen peroxide $(66.5 \%)$, discharge of medical waste in accordance with the legislation $(64.5 \%)$, cleaning and sterilization of the dental hand instruments immediately after usage (58.5\%) and asking children and parents to use hand sanitizer when leaving the clinic (52.5\%). Rarely used measures included fogging system for disinfection $(35.5 \%)$, ventilation and air-purifying system $(16 \%)$, ultraviolet radiation system $(9 \%)$, and high-efficacy particulate air (HEPA) filtration system (7.0\%).

Table 12. Infection control practices used by the participants/institutions after treatment.

\begin{tabular}{|c|c|c|}
\hline & $n$ & $(\%)$ \\
\hline Asking children and parents to use hand sanitizer when leaving the clinic. & 104 & 52.5 \\
\hline Disinfecting reusable personal protective equipment with $70 \%$ alcohol after each usage. & 136 & 68 \\
\hline $\begin{array}{c}\text { Disinfection of commonly used areas such as dental unit, dental light, dental X-ray } \\
\text { machine after each patient with } 70 \% \text { ethanol, } 0.1 \% \text { sodium hypochlorite, or } 0.5 \% \\
\text { hydrogen peroxide. }\end{array}$ & 133 & 66.5 \\
\hline Cleaning and sterilization of the dental hand instruments immediately after usage. & 117 & 58.5 \\
\hline Ventilation of the treatment room after each patient. & 170 & 85.0 \\
\hline $\begin{array}{l}\text { Regular disinfection of common areas, door handles, chairs and tables with } 0.1 \% \\
\text { sodium hypochlorite. }\end{array}$ & 145 & 72.5 \\
\hline Discharge of medical waste in accordance with the legislation. & 129 & 64.5 \\
\hline Fogging system for disinfection. & 71 & 35.5 \\
\hline High-efficacy particulate air (HEPA) filtration system. & 14 & 7.0 \\
\hline Ventilation and air-purifying System. & 32 & 16 \\
\hline Ultraviolet radiation system. & 18 & 9 \\
\hline
\end{tabular}

\section{Discussion}

This cross-sectional study, which assessed the knowledge, attitudes and practices of pediatric dentists during the COVID-19 lockdown period, is the first to be conducted among Turkish pediatric dentists and one of the first studies of its kind worldwide [11-14]. Additionally, this study revealed real-life evidence on the efficacy of the guidelines and protocols among Turkish pediatric dentists. In this study, most of the participating pediatric dentists were female ( $86 \%$ ) and only $14 \%$ were male, which indicates that the number of female pediatric dentists is higher than males in Turkey. Similar results were also reported by other studies [11-14]. In addition, the vast majority of participating pediatric dentists $(87 \%)$ were young, between the ages of 20 and 40 . This might be because of the web-based nature of the study, and the rate of participation of young people in such studies could be higher because they spend more time on the internet. Moreover, $64 \%$ of the study participants were academicians working in either state or private university hospitals; thus, because of their interest in scientific studies, their participation rate might be higher than others.

Along with the closures that occurred in many parts of the world during the COVID-19 lockdown period, dental clinics were also affected, and many of them were closed [15]. The results of this study show that the vast majority of pediatric dentists' (96\%) working time decreased during this period. Similarly, practice closures or reductions have been reported by previous studies [16-23]. Some reports in the literature have demonstrated that most dentists accepted that they were at high risk and were afraid of contracting/spreading the COVID-19 virus to their families [2,18,24,25]. Nevertheless, in this study, 75\% of all pediatric dentists continued to live with their families during the COVID-19 lockdown period. Similar findings were presented by Duruk et al. [2] and Hua et al. [20]. The results 
of this study reveal that, at the time of our survey study, pediatric dentists and people in their surroundings had low rates of COVID-19 disease. Similar observations were also reported in previous studies [17,22-24,26]. The reason for this result might be the closure of clinics at the beginning of the pandemic and the disruption to interpersonal contact.

The present study showed that $55 \%$ of all participants attended a webinar on COVID-19. Previous studies [2,11,13,20,27-32] showed the various rates of attendance of dentists at an education program on COVID-19. Contrary to these results, some researchers reported insufficient training $[12,14,33,34]$. In this context, continuous training programs are necessary in order to acquire perfect infection management skills for the present and future possible pandemics.

In order to provide adequate protection, dentists and other healthcare personnel should be aware of the symptoms and transmission routes of COVID-19 disease. Clinical findings of COVID-19 infection in children involve runny nose, fever, shortness of breath, dry cough, muscle or joint pain and gastrointestinal symptoms such as vomiting and diarrhea [35]. Most of the pediatric dentists in this study knew the main symptoms, such as fever, shortness of breath, dry cough, joint or muscle pain, sore throat and diarrhea. However, it was detected that non-respiratory symptoms were not well known. Nearly half of the pediatric dentists knew about sore eyes and vomiting. The least known symptoms were runny nose and skin rash. Cai et al. [36] reported that some COVID-19-positive children did not present respiratory symptoms as the first manifestation. Therefore, pediatric dentists should have information about non-respiratory symptoms as well as the main symptoms of COVID-19. Nevertheless, most of the pediatric dentists in this study were aware of the possible symptoms of COVID-19 that accompany an infection, in accordance with the previous studies [11,12,29-33,37-39]. Furthermore, most children can be asymptomatic, and do not show any warning signs to the practitioners; thus, asymptomatic and pre-symptomatic children significantly increase the transmission $[6,40,41]$. In this study, it was found that the vast majority of pediatric dentists (90\%) knew that COVID-19 disease could be asymptomatic.

The potential COVID-19 transmission routes comprise direct transmission with respiratory droplets through coughing and sneezing, contact with saliva, eyes and blood, indirect transmission through contact with fomites, and fecal-oral and airborne transmissions [3]. The results of this study reveal that transmission routes are well-known among Turkish pediatric dentists, but the least known transmission routes were fecal-oral transmission and blood. The aerosols generated during dental treatment, including blood, saliva and organic particles, cause air and environmental pollution in the clinic. Thus, it is very important for dentists to know that the virus can be transmitted through blood. When dental treatments creating aerosols are conducted, the spread of viruses, bacteria and germs increases because of the presence of blood and saliva [32]. In the study of Bekes et al. [12], more than $80 \%$ of pediatric dentists specified all the factors related to close contact with the infection. In another study by Moheb et al. [13], most pediatric dentists knew the droplet $(92.6 \%)$ and direct contact (65.8\%) modes, but only $34.2 \%$ identified the indirect contact mode of infection. Maru et al. [11] reported that $66.7 \%$ of Indian pediatric dentists were informed about the transmission routes of COVID-19 infection. Most of the pediatric dentists in this study were knowledgeable about the possible COVID-19 transmission routes, which is in line with other studies [29-32,34,37-39,42,43] in the literature. On the contrary, Nasser et al. [33] reported poor knowledge among dentists in Lebanon related to transmission routes of the disease. Being conscious about the symptoms and transmission routes of COVID-19 is critical in order to not neglect the necessary measures during dental procedures.

The level of knowledge of participating pediatric dentists was also evaluated by asking about some important information related with COVID-19 besides the symptoms and transmission routes. Among these, all pediatric dentists accepted that dental healthcare workers are at high risk of being infected with COVID-19 when compared with the general population. Most of the dentists in other reports $[12,17,26,31-33,44,45]$ expressed a similar 
opinion. Estrich et al. [26] declared that non-clinical activities in the dental office could be a reason for transmission. Banakar et al. [5] stated that dental settings contribute to the transmission of COVID-19 through AGPs. In the current study, all pediatric dentists stated that the statement "Aerosol and droplets formed during dental treatment, increase the risk of spread and transmission of COVID-19" was true. Similarly, in the study of Candeiro et al. [39], 98.5\% of the participants affirmed that COVID-19 can be transmitted during dental procedures. Furthermore, in another study [31], nearly $74 \%$ of participants said that the dental treatments performed by using high-speed handpieces and ultrasonic scalers elevate the risk of virus transmission because of the creation of aerosol particles.

In this study, nearly all pediatric dentists knew that children can be asymptomatic or present mild, nonspecific symptoms, and accepted that asymptomatic/pre-symptomatic patients in the incubation period could be carriers of COVID-19. Similar observations were reported by Bekes et al. [12], Arora et al. [31], and Maru et al. [11]. On the contrary, in the study of Nasser et al. [33], 88.3\% of Lebanese dentists agreed with the statement "Coronavirus does not infect children". Ahmed et al. [34] reported that most of the participants (78.7\%) in their study knew that COVID-19 affects people from older age groups, but only $7.6 \%$ knew that infants could also be affected. In the study of Martina et al. [24], the majority of dentists accepted that adolescents and children had the same infection risk as adults. Asymptomatic carriers are the main cause of transmission and, if present, these mild symptoms can be easily confused with flu-like symptoms [31]. For this reason, dentists should consider each patient as COVID-19-positive and take the necessary precautions during dental treatments, as nearly all pediatric dentists confirmed this statement in our study. Furthermore, pediatric patients present additional risks of transmission due to the use of appliances, the difficulty in using PPE, and patients coming to the clinic with one or more parent [46]. The results of this study show that $98.5 \%$ of pediatric dentists accepted that this information was true.

It is important to have knowledge of the fact that wearing any type of mask is not recommended for children younger than 2 years of age and children unable to remove their mask without assistance. This is because of their small airways and the increased risk of suffocation [47]. Unfortunately, only $57.5 \%$ of participants knew this information in our study. Moreover, among the detection methods of COVID-19, nucleic acid-based detection has become reliable and rapid, although a negative result does not mean that the possibility of COVID-19 infection can be rejected, and it should not be considered as the only criteria for patient management or treatment determination [48]. In the current study, nearly all pediatric dentists knew that a single negative PCR test result does not exclude the possibility of COVID-19 infection among suspected patients. Together with this, saliva could be a fast, inexpensive and non-invasive method of detecting COVID-19 disease [49]. In this study, $75 \%$ of participants agreed that the statement "Virus detection from saliva samples can be a diagnostic method" was true.

Considering the present study, the vast majority of pediatric dentists had a good level of knowledge about COVID-19 disease. Although questions evaluating the knowledge level of dentists might be different among studies, previous studies have also found that dentists have a good knowledge level as well $[11,12,28,30,34,50]$. The results of this study showed that the knowledge level of dentists about COVID-19 is sufficient, but it is recommended that information should be continuously updated in the following periods according to the course of the disease, in order to optimize the management of COVID-19.

Many countries have restricted dental treatments and only permitted emergency treatments during the COVID-19 lockdown period; however, these arrangements were not long-sighted or economical. Thus, infection control regimens should be revised for the current pandemic and subsequently for the long-term endemic period [51]. There are important infection control measures and precautions that each institution should implement before conducting dental treatments [51-53]. Among these, "posting visual public notices for all visitors at the building entrances including signs and symptoms of COVID-19 and warning not to enter the facility if they are exhibiting any of these symptoms" was imple- 
mented by nearly $79 \%$ of pediatric dentists' institutions. In addition, posting signs and posters at the entrance of the waiting room and in the areas visible to patients to provide instructions about social distancing, hand hygiene and respiratory hygiene measures was conducted by $81.8 \%$ of participants. Similarly, Moheb et al. [13] reported that nearly $53 \%$ of dentists printed and placed patients' instructions for cough etiquette and social distancing. As another infection control measure, $60 \%$ of participants triaged dental patients by phone or online conferencing in order to obtain information on children's health and COVID-19 risk status, and to determine emergency dental problems in the current study. Furthermore, nearly the same percentage of pediatric dentists completed their patients' control appointments via phone, WhatsApp and social networks. Similarly, triaging dental patients was reported to have been conducted in previous studies [13,14,16,17,22,23,42,44,54,55].

Along with the infection control measures, employing pre-control staff at the institution for screening temperatures with a non-contact thermometer and checking the apropriate use of face masks was conducted by $86.4 \%$ of participants in the current study. This finding was found to be consistent with those of previous studies $[14,18,21,26,27,54,56]$, but it contradicted the findings of Cagetti et al. [17], Consolo et al. [22] and Izzetti et al. [16], where taking the temperature of the patients before dental treatments was a practice that was implemented at a lower rate. Moreover, questioning the travel history and presence of symptoms of everyone before entering the building was conducted by $72.2 \%$ of participants in this study. Similarly, Ates et al. [54] reported that before the dental treatments, 73.4\% asked if the patient had symptoms, shortness of breath, cough or fever. Contrarily, in the study of Duruk et al. [2], only $4 \%$ of participants conducted this procedure. In addition, nearly $70 \%$ of pediatric dentists obtained medical and dental anamnesis from children and parents. The dental management of children with special needs and medically compromised children requires careful consideration of their health condition as well during the COVID-19 pandemic era [40].

As another critical infection control measure, hand washing and/or using alcoholbased disinfectants before entering the operating room should be encouraged for all patients [32]. In our study, placing hand sanitizer and asking children and parents to use it when entering the clinic was conducted by $73.2 \%$ of participants. Moheb et al. [13] reported that nearly $93 \%$ of dentists offered alcohol hand sanitizers to patients and parents. In another study, asking patients to wash their hands was reported by nearly $78 \%$ of dentists in North Italy [17] and nearly 65\% of dental hygienists in Italy [42]. According to Al-Khalifa et al. [56], 68\% of participants reported patients' hand washing/sanitizing before going into the waiting area. However, in the study of Putrino et al. [32], the usage of alcohol disinfectant at the entrance for hand cleaning was reported by only $9.7 \%$ of participants. Additionally, scheduling the appointments of patients at times not close to each other in order to prevent crowding and the establishment of the time required for disinfection and ventilation was conducted by $71.7 \%$ of participants in our study. This finding is in accordance with the studies conducted by Bekes et al. [12], Cagetti et al. [17], Nasser et al. [33], and Consolo et al. [22]. Furthermore, applying social distancing rules in the waiting room, and asking some of the patients to wait outside the building if necessary, was conducted by $81.3 \%$ of participants. Similar procedures were also applied in previous studies $[13,14,16,17,23,42,56]$.

Ensuring that the pediatric patient comes to the clinic with a single accompanying person was reported by $67.5 \%$ of participants in this study. Similarly, Moheb et al. [13] reported that nearly $97 \%$ of dentists instructed parents that only one accompanying person was allowed with the child. The results of the study conducted by Bekes et al. [12] showed that nearly $78 \%$ of dentists allowed children to come to their appointments with only one accompanying person. According to Allevi et al. [21], one of the most frequently used methods was limiting relatives' visits (96\%). Izzetti et al. [16] also reported that 97.5\% of participants discouraged the presence of accompanying people. Lastly, removing toys or reading materials that could be touched by other children was conducted by $56.6 \%$ of participants in this study. In line with our findings, dentists in other studies $[13,14,16,17,42]$ 
removed reading materials and other materials that are not easily disinfected. According to this information, it is obvious that the vast majority of pediatric dentists in this study satisfactorily conducted most of the mentioned infection control measures before the dental treatments. However, procedures including removing all unnecessary materials in the dental office, triaging patients and only allowing one person to accompany the child could be better implemented.

CDC and ADA guidance reports that active COVID-19 patients and patients exposed to a person with confirmed/suspected COVID-19 infection, and patients who had been in countries under a travel ban, should not be treated in dental clinics. If emergency/urgent dental care is needed, patients should be assessed for COVID-19 symptoms. Patients who have/do not have fever together with signs and symptoms of acute respiratory infection need to go to the emergency department of a hospital for infection control and treatment measures. If patients do not have fever and signs and symptoms of acute respiratory infection, or only have fever, they can be treated at the dental clinic because the fever might because of a dental infection [6,52]. In the current study, among the pediatric dentists who encountered a child patient or parent who had signs and symptoms of acute respiratory infection, nearly $64 \%$ of them referred the patient to a hospital with a medical mask without conducting the treatment in accordance with the ADA and CDC guidelines, and 4.5\% refused to treat the patient and asked them to leave the clinic. Among pediatric dentists who did not encounter a child patient or parent who had signs and symptoms of acute respiratory infection, nearly $70 \%$ reported that they referred the patient to a hospital with a medical mask without conducting the treatment, in line with the recommendations, and nearly $14 \%$ refused to treat the patient and asked them to leave the clinic. Moheb et al. [13] reported that nearly $55 \%$ of dentists prescribed medication if they faced a patient with fever and no other signs/symptoms of COVID-19 infection. Moreover, researchers also reported that $40 \%$ of dentists also chose to control the situation with medicines if they were faced with a patient who did not report any symptoms but the dentist observed signs of respiratory illness. Similarly, Nasser et al. [33] showed that more than $80 \%$ of the dentists were afraid to treat a patient suspected of or confirmed as having COVID-19. In another study by Khader et al. [38], nearly $44 \%$ of dentists declared that they would refer the patient to the hospital without conducting treatment, $4.6 \%$ declared that they would refuse to treat the patient and ask them to leave the clinic, and nearly half of the dentists would treat the patient and ask them to go to the hospital when they were faced with a patient coughing and sneezing in their dental clinic. Furthermore, in the study of De Stefani et al. [29], nearly $66 \%$ of dentists said they would have refused to treat a patient suffering from a runny nose and cough.

In our study, among the pediatric dentists who encountered a child patient or parent who had signs and symptoms of acute respiratory infection, nearly $32 \%$ of them referred these patients to a hospital after treating the patient. Among dentists who did not encounter a child patient or parent who had signs and symptoms of acute respiratory infection, nearly $15 \%$ reported that they referred these patients to a hospital after treating them. Similarly, in the study of Bekes et al. [12], 31\% of pediatric dentists had self-confidence in the treatment of suspected COVID infections. Hua et al. [20] reported that nearly $64 \%$ of participants wanted to treat patients with suspected/confirmed COVID-19 infection. Maru et al. [11] reported that $57.5 \%$ of pediatric dentists had self-confidence in conducting treatment on children with suspected COVID-19; however, $10.80 \%$ of pediatric dentists exhibited no confidence. The results of the study conducted by Arora et al. [31] showed that nearly $42 \%$ of dentists displayed a positive attitude towards providing emergency dental treatment to COVID19-positive patients. In the study of Becker et al. [44], it was recommended that COVID-19-positive patients' dental treatments should be performed at dental university hospitals in isolated rooms. Thus, it was strongly recommended that emergent COVID-19 positive/suspected patients should be treated in the hospital's separate airborne infection isolation rooms (AIIR), which are kept under negative pressure with an HEPA filter. In addition, high-level protection with full usage of PPE is needed. 
Furthermore, healthcare workers should follow donning and doffing procedures. It is important to know that COVID-19-positive/suspected patients should not be treated in a room that recirculates air within the hospital and without appropriate PPE usage [27,57]. Most of the pediatric dentists in this study referred or considered referring patients who had signs and symptoms of acute respiratory infection to a hospital with medical masks without conducting the treatment, or refused to treat the patient. If the necessary facilities such as AIIR including an HEPA filter are not available, this approach is more acceptable than conducting dental treatments of COVID-19-positive/suspected patients in the same environment with other patients.

When pediatric dentists were asked about the dental procedures they performed during the COVID-19 lockdown period, the vast majority (82\%) said they only performed emergency dental treatments according to Turkish government recommendations. In line with the current report, the majority of previous studies $[2,12,13,15,16,22,30,32,39,54,55,58,59]$ showed that dental practices were reduced to urgent/emergency procedures during the COVID-19 quarantine period. However, Nibali et al. [60] reported that most of the practitioners had completely ended all dental activities. Emergent dental situations include facial swellings, severe dental/facial pain that cannot be controlled with advised medications, traumatic dental injuries such as severe luxation injuries, complicated crown fractures, avulsions of permanent incisors, soft tissue infections, uncontrollable post-operative bleeding, conditions worsening systemic medical conditions, and suspected oral cancer [61]. Furthermore, in our study, the most common emergency situations were reported as severe pain caused by pulpal inflammation (94\%), abscesses or bacterial infection causing localized pain and extraoral swelling (86.5\%), luxations/dental avulsions (41\%), dental fractures causing pain, or soft tissue injuries caused by trauma (35.5\%). Ilyas et al. [61] reported irreversible pulpitis, Moheb et al. [13] reported severe pain, infection and trauma, Üstün et al. [62] reported severe dental pain because of pulpal inflammation and swelling, Faccini et al. [58] reported toothache (71.4\%), broken restorations (40.4\%) and dental trauma $(37.3 \%)$, Alsaleh et al. [14] reported abscesses (51.8\%) and cellulitis (44.6\%) in Jordan and abscesses $(44.6 \%)$ and pulpitis (35.5\%) in India, Izzetti et al. [16] reported pulpitis, prosthesis de-cementation and abscesses, and Sinjari et al. [55] reported severe dental pain, swelling and dental trauma as the most common emergency situations managed. Thus, the findings of this study were found to be in accordance with those others $[13,14,16,55,58,61,62]$. However, differently from our findings, Limbu et al. [63] reported exfoliating mobility (23.3\%), acute pulpitis (5.8\%) and dental abscesses (22.1\%), and Martinho and Griffin [18] reported trauma $(82.1 \%)$ followed by swelling $(81.9 \%)$ and pain $(76.1 \%)$ as dental emergencies.

In order to achieve efficient infection control, dentists and all healthcare workers in the dental clinic should pay attention to appropriate PPE usage while working in the dental clinic, especially during the COVID-19 era [33]. PPE includes disposable scrubs, shoe covers, hair covers, goggles, gloves, gown, masks and face shields. While conducting non-AGPs, work clothes, usage of goggles/face shields, fluid-resistant surgical masks, disposable gloves, disposable aprons and hair covers are recommended. In addition to all these protections, the usage of particulate respirators, disposable gowns, medical protective clothing and shoe covers are required during AGPs. The most effective/protective masks are N99/N100/FFP2/FFP3/N95 masks [64,65]. Scrubs (87\%) and surgical masks (90\%) were found to be widely used in both AGPs and non-AGPs in the current study. Similarly, Duruk et al. [2], Estrich et al. [26], and Izzetti et al. [16] also reported nearly $86 \%, 99 \%$ and $98 \%$ mask usage, respectively. Disposable gloves $(92.5 \%)$ were found to be used widely in both AGPs and non-AGPs in line with previous studies $[2,14,17]$. Face shield $(83 \%)$ usage was found to be similar to that reported by Sinjari et al. [55]. In line with our findings, in studies by Alsaleh et al. [14] and Duruk et al. [2], face shield usage was shown to have high percentages. Furthermore, goggles $(71 \%)$, disposable surgical gowns $(70.5 \%)$, and disposable medical caps (83.5\%) were found to be used widely in both AGP and non-AGPs in this study. Alsaleh et al. [14] reported a similar rate of goggle usage in India (75.2\%). Duruk et al. [2], Izzetti et al. [16] and Sinjari et al. [55] reported that nearly $46 \%, 80 \%$ and 
$82 \%$ of participating dentists used disposable aprons/gowns. Martinho and Griffin [18] showed that $36.8 \%$ of participants used protective suits; however, $24 \%$ of pediatric dentists used protective coveralls in this study. Moreover, disposable medical caps $(83.5 \%)$ were found to be widely used in both AGPs and non-AGPs. Similarly, Izzetti et al. [16], and Duruk et al. [2] reported medical cap usage rates of $84.4 \%$ and $56 \%$, respectively.

When we consider the usage of particulate respirators, Alsaleh et al. [14] reported N95 respirator usage rates of $80.4 \%$ in Jordan and $87.6 \%$ in India. Ammar et al. [37] reported N95/FFP2 usage of 91.7\%. Martinho and Griffin [18] reported that the usage rate of N95 respirators was $83.1 \%$. N95 respirator usage was found to be lower in our study, where $21 \%$ of pediatric dentists only used AGPs and 51\% used both AGPs and non-AGPs. However, lower percentages than in this study were also reported by Duruk et al. [2] (12.36\%) and Ahmed et al. [34] (11.6\%). In addition, FFP2 respirators were used only in AGPs by $16 \%$, and were used in both AGPs and non-AGPs by $43.5 \%$. Cagetti et al. [17] and Izzetti et al. [16] reported rates of usage of FFP2/FFP3 masks of $54.84 \%$ and $15.4 \%$, respectively. Sinjari et al. [55] reported FFP2 usage of nearly $62 \%$ and Bekes et al. [12] reported rates of nearly $45 \%$ for FFP2 and $60 \%$ for FFP3e. Estrich et al. [26] also showed that dental practitioners wore surgical masks over particulate respirators, and replaced the surgical masks more often. Considering PPE usage, it was detected in our study that pediatric dentists attach importance to the use of PPEs. Scrubs, surgical masks, disposable gloves, goggles, face shields, disposable surgical gowns, and disposable medical caps were found to be widely used in both AGPs and non-AGPs. However, the usage of particulate respirators such as N95, FFP2/FFP3 and overshoes should be increased. The reasons for this result could be that the dentists thought that a surgical mask combined with a face shield could offer sufficient protection, the fact that wearing a respirator for long time is not easy, and the high costs of respirators [13]. Furthermore, difficulty in accessing PPE supplies could be another reason [16].

Knowing the correct sequence for donning and doffing PPE is also important, besides using the required PPE, among dental practitioners in order to reduce contamination $[57,66]$. Furthermore, after the dental treatment, patients and the dental team should leave the clinic from separate exits, and all clinical personnel should pay attention to doffing their PPE in the buffer zone [67]. In our study, most of the pediatric dentists $(84 \%)$ reported that they paid attention to the proper order of donning and doffing their PPEs; however, only $55 \%$ paid attention to removing their and other dental healthcare workers' PPEs in a separate isolation room. Bekes et al. [12] reported that nearly $52 \%$ of the dentists knew the correct sequence of donning PPE (gown, mask, eye protection, gloves). Maru et al. [11] showed that $66.5 \%$ and $64.8 \%$ of Indian pediatric dentists knew the correct sequence of donning (gown, mask, eye protector, gloves) and doffing PPE (gloves, eye protector, gown, mask), respectively.

The parents should prepare their children mentally prior to dental appointments because the dental team behind the PPE may frighten the child [68]. Successful behavior management is crucial for pediatric dentists because uncooperative, crying children spread more aerosols than calm ones. Thus, in order to reduce the anxiety of children related to the dental team's PPEs, including face mask, it is recommended that they put them on in front of the children and explain the necessity of this equipment [40]. In our study, most of the pediatric dentists thought that their PPE increased the anxiety levels of children. Furthermore, more than half of participants explained their PPE to their pediatric patients as them wearing an astronaut suit, $26 \%$ said they had become a superhero, $59.5 \%$ explained the reason of usage and $21.5 \%$ did not give any explanation. In another study, nearly $28 \%$ of dentists reported that children did not react differently, nearly $32 \%$ reported children were interested, nearly $30 \%$ reported children were distressed and worried, but nearly $10 \%$ of dentists reported that they did not use advanced PPE while treating children [13]. Additionally, extra PPE covers facial expressions and complicates behavior management in children. Thus, PPE could be modified in order to make it more child friendly [14]. Before dental treatment, meeting with the pediatric patient via video call without wearing 
PPE and introducing PPE with the tell-show-do technique, using colorful/painted gowns, and placing stickers or the dentist's picture on the PPE were suggested modifications for pediatric dental clinic practices [14].

When we evaluated the infection control measures used during dental treatments, using hand instrumentation, avoiding high-speed handpiece/ultrasonic instruments/air water syringe usage, and the treatment of only one patient in a room were conducted by most of the pediatric dentists. Moheb et al. [13] reported that nearly $85 \%$ of dentists used hand instruments as much as possible to avoid aerosols, and nearly $84 \%$ minimized the use of a three in one syringe. Additionally, in another study, most of the dentists (88.5\%) made the effort to reduce aerosol formation [16]. Ates et al. [54] reported that half of the participants used slow-speed handpieces without water to minimize contamination risk. However, in this study, only 49 pediatric dentists used this approach. The use of a dental handpiece with an anti-retraction function was reported as a preventive measure [42], but only five pediatric dentists reported using those instruments. Among the infection control measures, only $39 \%$ of pediatric dentist said they did not allow parents into the treatment room. The reason for this result might be due to the fact young children in particular do not want to be separated from their families during dental treatments. If the child does not want to enter the treatment room alone, a maximum of one parent should be accepted, and other accompanying people should be prevented from entering the treatment room. In addition, chemomechanical caries removal was only conducted by nine pediatric dentists in our study. This might be related to the preference for conventional treatments among pediatric dentists before the COVID-19 pandemic period and the lack of essential dental materials. Furthermore, ITR were conducted by nearly $34 \%$ of pediatric dentists, and this result might be because of the delay of routine dental practices and the treatment of emergency dental treatments, mainly abscesses or bacterial infection causing localized pain and extraoral swelling (86.5\%). However, since it is not possible to carry out only emergency treatments, approaches that prevent aerosol formation, such as chemomechanical caries removal, ART, ITR and SDF, should be preferred for routine dental treatments after the quarantine period in order to reduce aerosol formation and to prevent contamination with SARS-COV2 during long-term pandemic conditions. Rubber dam usage also reduces the risk of aerosols during the COVID-19 pandemic period. However, in our study, rubber dam usage was found to be unsatisfactory and lower than in other studies conducted by Moheb et al. [13], Izzetti et al. [16], and Sinjari et al. [55]. The findings of Duruk et al. [2] (13.84\%) and Ataş and Yıldırım [69] (15.9\%) also revealed that rubber dam usage was infrequent. Moheb et al. [13] declared that it is not always feasible to excavate caries only using hand instruments; the application of a rubber dam is not possible for some children, and an air water syringe might be required. Even in such cases, dentists have to do their best to reduce aerosol formation.

Among the infection control methods used during dental treatments, the four-handed technique was used by nearly $30 \%$ of participants in this study. Similarly, $37.8 \%$ of dentists used this technique in the study of Izzetti et al. [16]. Preprocedural oxidative or antimicrobial mouth-rinse usage was reported by nearly $34 \%$ of pediatric dentists in this study. Moheb et al. [13] reported that nearly 56\% and Al-Khalifa et al. [56] reported that $47 \%$ of dentists preferred patients using antiseptic mouth rinse before dental treatments. Furthermore, high-volume saliva ejector usage was reported by nearly $35 \%$ of participants; however, Moheb et al. [13], Duruk et al. [2], and Ataş and Yıldırım [69] reported strong saliva absorber usage rates of $87.2 \%, 63.79 \%$ and $42.4 \%$, respectively. In the study of Martinho and Griffin [18], nearly $17 \%$ of participants reported usage of an oral aerosol vacuum. In another study by Estrich et al. [26], 17\% of participants said they used an extraoral suction device. Al- Khalifa et al. [56] reported that $59 \%$ of participating dentists did not use extraoral suction systems. Unfortunately, in the current study, only $6.5 \%$ of participants used a dental extraoral suction system. Lastly, in order to prevent the spread of infections, ensuring good hand hygiene is one of the most efficient methods. A two before (before conducting examination and before performing dental treatment) and three after 
(after touching the patient, after touching the undisinfected surroundings/equipment, and after touching blood/wound/oral mucosa/damaged skin) hand hygiene system should be conducted by the dental team to strengthen hand hygiene [10]. The results of this study show that nearly $80 \%$ of the pediatric dentists encountered a situation such as burning, stinging, itching or dryness on the skin due to frequent hand cleaning and the long-term use of PPEs. However, it was detected that the recommended two before three after hand hygiene protocol was not well known among pediatric dentists in our study. According to our findings, it is obvious that pediatric dentists wash their hands before and after the procedures, and struggle to achieve sufficient disinfection; however, increased hand hygiene following the two before three after hand hygiene protocol should definitely be performed to increase protection against the COVID-19 disease. Therefore, dentists should be familiar with the concept of two before three after hand hygiene. To conclude, in our study, the most crucial control measures, such as the treatment of one patient in a room, not using high-speed handpieces and ultrasonic instruments, not using air water syringes, and preference for hand instrumentation, were found to be more widely used by pediatric dentists than other precautions. However, the lack of implementation of rubber dams, four-handed dentistry, dental extraoral suction systems, high-volume saliva ejectors and two before three after hand hygiene should be increased via education programs.

Another important point that needs to be considered is the radiographic evaluation of patients during the COVID-19 pandemic period. If radiographs are required from patients, extraoral radiographs should be preferred instead of intraoral radiographs in order not to stimulate the secretion of saliva and coughing [70]. In line with the recommendations, most of the pediatric dentists obtained panoramic radiographs in this study. Similarly, Moheb et al. [13] also reported that nearly $62 \%$ of dentist shifted from intraoral to extraoral radiographs, if available. In another study, Ammar et al. [37] reported that nearly $60 \%$ of dental academics used extraoral radiographs rather than intraoral radiographs.

The dental management of uncooperative patients during the COVID-19 lockdown period is also an issue that needs to be carefully evaluated. Similar to our study, Moheb et al. [13] reported that the majority of dentists (73\%) did not use sedation or general anesthesia during the pandemic period. Additionally, they reported that nearly $70 \%$ of pediatric dentists refused to use physical restraining. A similar finding was observed in our study, as only $8 \%$ of pediatric dentists used physical restraining in order to control children's sudden movements. Alsaleh et al. [14] reported that most dentists $(71.1 \%$ in India and $80.4 \%$ in Jordan) did not use $\mathrm{N} 2 \mathrm{O}$ sedation for their pediatric patients. For less aerosol production, in India ART (52.1\%) and SDF (28.9\%), and in Jordan the Hall technique $(26.8 \%)$ and ART $(25.0 \%)$, were performed. In the current study, ART (33\%) was the most preferred treatment in accordance with Alsaleh et al. [14]; however, SDF and the Hall technique were used less than in the study by Alsaleh et al. [14]. As previously mentioned, minimally invasive treatment approaches were not widely used since most of the pediatric dentists in our study only performed emergency treatments during the lockdown period. However, lockdown periods are not permanent and they are rotative; thus, in order to reduce the risk of transmission, treatments that reduce aerosol formation should be used widely in dental practice.

Among the infection control measures performed after dental treatments, the disinfection of commonly used areas, such as dental units, dental lights and dental X-ray machines, after each patient was conducted by $66.5 \%$ of pediatric dentists in this study. Similarly, in the studies of Bontà et al. [42] and Cagetti et al. [17], 74.13\% and $80.49 \%$ of participants reported that they removed and disinfected disposable protective devices, respectively. In another study, nearly $68 \%$ of healthcare professionals said they applied universal precautions for infection control [34]. Khader et al. [38] reported that nearly $94 \%$ of participants routinely cleaned and disinfected surfaces that had been in contact with known or suspected patients. On the other hand, the regular disinfection of common areas, door handles, chairs and tables was also deemed to be important and conducted by $72.5 \%$ of pediatric dentists in this study. Similarly, in the study of Estrich et al. [26], almost all 
practicing dentists reported that they disinfected commonly touched equipment and surfaces. Similar observations were reported in previous studies $[17,32,33,42,71]$. Furthermore, the ventilation of the treatment room after each patient was conducted by $85 \%$ of pediatric dentists in our study. In accordance with our findings, in the studies of Bontà et al. [42] and Izzetti et al. [16], nearly $71 \%$ and $98 \%$ of participants provided room ventilation after dental treatments, respectively. However, Putrino et al. [32] reported that less (14.9\%) participants ventilated the treatment room between patients. Air-purifying systems were found to be used by only $16 \%$ of pediatric dentists in this study. Martinho and Griffin [18] indicated that $42.3 \%$ of endodontists could implement an air-purifying unit. In another study by Huntley et al. [27], $42.5 \%$ of the participants reported that they had no access to an air-purifying unit. Among the infection control measures mentioned, the least conducted measures were a fogging system for disinfection (35.5\%) and a HEPA filtration system (7\%). Similarly, Alsaleh et al. [14] reported that the least conducted measure was the use of HEPA filters in India (41.3\%) and in Jordan (8.9\%).

Infection control measures after dental treatments are mandatory, and in our study, those precautions were found to be satisfactory applied, such as ventilation of the treatment room after each patient, regular disinfection of common areas in the dental clinic and treatment room, disinfection of reusable PPEs, discharge of medical waste, cleaning and sterilization of the dental hand instruments immediately after usage, and making children and parents use hand sanitizer when leaving the clinic. However, the rarely used measures were fogging systems for disinfection, ventilation and air conditioning systems, ultraviolet radiation systems, and HEPA filtration systems.

\section{Conclusions}

The findings of the current study show that Turkish pediatric dentists had a good level of knowledge about COVID-19, sufficient to perform dental treatments safely and not neglect the necessary precautions during dental procedures. Turkish pediatric dentists satisfactorily conducted most of the infection control measures before and after the dental treatments, and they attached importance to the use of PPEs; however, infection control measures during the dental treatments could be better implemented. At the beginning of the pandemic, most pediatric dentists only performed emergency treatments; however, lockdown periods are not long-lasting and they are rotative. Thus, in order to reduce the risk of transmission, minimally invasive approaches should be used widely in routine dental practices. Along with all precautions, the vaccination of healthcare workers and requesting a recent test result from patients that shows the absence of COVID-19 before dental appointments can be added to the effective infection control measures. Additionally, pediatric dentists should continue to follow local and universal guidelines, and education programs should be implemented frequently in order to keep COVID-19 management strategies up to date.

Supplementary Materials: The following are available online at https:/ /www.mdpi.com/article/10 .3390/medicina57111140/s1. Supplementary File S1: Survey Questionnaire.

Author Contributions: Conceptualization, Y.K., D.A.-B., S.A.; methodology, Y.K., D.A.-B., S.A.; formal analysis, Y.K., D.A.-B.; investigation, Y.K., D.A.-B., S.A.; resources, Y.K., D.A.-B., S.A.; data curation, Y.K., D.A.-B., S.A.; writing—original draft preparation, D.A.-B., Y.K.; writing-review and editing, Y.K., D.A.-B., S.A.; visualization, Y.K., D.A.-B., S.A.; supervision, D.A.-B., S.A. All authors have read and agreed to the published version of the manuscript.

Funding: This research received no external funding.

Institutional Review Board Statement: The study was conducted according to the guidelines of the Declaration of Helsinki, and approved by the Institutional Review Board (or Ethics Committee) of Near East University (protocol code: YDU/2020/79-1083; 28 May 2020).

Informed Consent Statement: Informed consent was obtained from all participants involved in the study. 
Data Availability Statement: The data that support the findings of this study are available on request from the corresponding author.

Acknowledgments: We would like to thank the Turkish Association of Paediatric Dentistry and all pediatric dentists for their contributions to this study.

Conflicts of Interest: The authors declare no conflict of interest.

\section{References}

1. Lai, C.C.; Shih, T.P.; Ko, W.C.; Tang, H.J.; Hsueh, P.R. Severe acute respiratory syndrome coronavirus 2 (SARS-CoV-2) and coronavirus disease-2019 (COVID-19): The epidemic and the challenges. Int. J. Antimicrob. Agents 2020, 55, 105924. [CrossRef] [PubMed]

2. Duruk, G.; Gümüşboğa, Z.Ş.; Çolak, C. Investigation of Turkish dentists' clinical attitudes and behaviors towards the COVID-19 pandemic: A survey study. Braz. Oral Res. 2020, 34,1-12. [CrossRef] [PubMed]

3. Ferrazzano, G.F.; Ingenito, A.; Cantile, T. COVID-19 disease in children: What dentists should know and do to prevent viral spread. The Italian point of view. Int. J. Environ. Res. Public Health 2020, 17, 3642. [CrossRef]

4. Meng, L.; Hua, F.; Bian, Z. Coronavirus disease 2019 (COVID-19): Emerging and future challenges for dental and oral medicine. J. Dent. Res. 2020, 99, 481-487. [CrossRef] [PubMed]

5. Banakar, M.; Lankarani, K.B.; Jafarpour, D.; Moayedi, S.; Banakar, M.H.; MohammadSadeghi, A. COVID-19 transmission risk and protective protocols in dentistry: A systematic review. BMC Oral Health 2020, 20, 1-12. [CrossRef]

6. Ren, Y.F.; Rasubala, L.; Malmstrom, H.; Eliav, E. Dental care and oral health under the clouds of COVID-19. JDR Clin. Transl. Res. 2020, 5, 202-210. [CrossRef]

7. Mallineni, S.K.; Innes, N.P.; Raggio, D.P.; Araujo, M.P.; Robertson, M.D.; Jayaraman, J. Coronavirus disease (COVID-19): Characteristics in children and considerations for dentists providing their care. Int. J. Paediatr. Dent. 2020, 30, 245-250. [CrossRef]

8. Available online: https://turkpedo.org/covid-19-2/ (accessed on 27 August 2021).

9. Ayyed, A.B. Dental Practice Infection Control Measurements: Coronavirus Disease (COVID-19) Outbreaks. Int. J. Clin. Pediatr. Dent. 2020, 13, 279. [CrossRef]

10. Bhanushali, P.; Katge, F.; Deshpande, S.; Chimata, V.K.; Shetty, S.; Pradhan, D. COVID-19: Changing trends and its impact on future of dentistry. Int. J. Dent. 2020, 2020, 8817424. [CrossRef]

11. Maru, V.; Padawe, D.; Singh, A.; Takate, V.; Dighe, K.; Singh, S. Awareness, Perception, Attitude Regarding CoViD-19 and Infection Control among Indian Pediatric Dentists: A Cross Sectional Study. J. Clin. Pediatr. Dent. 2020, 44, 211-220. [CrossRef]

12. Bekes, K.; Ritschl, V.; Stamm, T. COVID-19 pandemic and its impact on pediatric dentistry in Austria: Knowledge, perception and attitude among pediatric dentists in a cross-sectional survey. J. Multidiscip. Healthc. 2021, 14, 161. [CrossRef] [PubMed]

13. Moheb, D.; Nasr, R.A.; Azab, M.M. Pediatric Dentists in the Time of COVID-19 Pandemic; the Challenges and Burden. Egypt. Dent. J. 2021, 67, 85-99. [CrossRef]

14. Alsaleh, M.M.; Sabbarini, J.M.; Al-Batayneh, O.B.; Khader, Y.S. Changes in behavior management and treatment modalities in pediatric dentistry during covid-19 pandemic. Int. J. Clin. Pediatr. Dent. 2020, 13, S125. [CrossRef]

15. Isiekwe, I.G.; Adeyemi, T.E.; Aikins, E.A.; Umeh, O.D. Perceived impact of the COVID-19 pandemic on orthodontic practice by orthodontists and orthodontic residents in Nigeria. J. World Fed. Orthod. 2020, 9, 123-128. [CrossRef]

16. Izzetti, R.; Gennai, S.; Nisi, M.; Barone, A.; Giuca, M.R.; Gabriele, M.; Graziani, F. A perspective on dental activity during COVID-19: The Italian survey. Oral Dis. 2021, 27, 694-702. [CrossRef]

17. Cagetti, M.G.; Cairoli, J.L.; Senna, A.; Campus, G. COVID-19 outbreak in North Italy: An overview on dentistry. A questionnaire survey. Int. J. Environ. Res. Public Health 2020, 17, 3835. [CrossRef]

18. Martinho, F.C.; Griffin, I.L. A cross-sectional survey on the impact of Coronavirus disease 2019 on the clinical practice of endodontists across the United States. J. Endod. 2021, 47, 28-38. [CrossRef]

19. Maffia, F.; Fontanari, M.; Vellone, V.; Cascone, P.; Mercuri, L.G. Impact of COVID-19 on maxillofacial surgery practice: A worldwide survey. Int. J. Oral Maxillofac. Surg. 2020, 49, 827-835. [CrossRef]

20. Hua, F.; Qin, D.; Yan, J.; Zhao, T.; He, H. COVID-19 related experience, knowledge, attitude, and behaviors among 2669 orthodontists, orthodontic residents, and nurses in China: A cross-sectional survey. Front. Med. 2020, 7, 481. [CrossRef]

21. Allevi, F.; Dionisio, A.; Baciliero, U.; Balercia, P.; Beltramini, G.A.; Bertossi, D.; Bozzetti, A.; Califano, L.; Cascone, P.; Colombo, L. Impact of COVID-19 epidemic on maxillofacial surgery in Italy. Br. J. Oral Maxillofac. Surg. 2020, 58, 692-697. [CrossRef] [PubMed]

22. Consolo, U.; Bellini, P.; Bencivenni, D.; Iani, C.; Checchi, V. Epidemiological aspects and psychological reactions to COVID-19 of dental practitioners in the Northern Italy Districts of Modena and Reggio Emilia. Int. J. Environ. Res. Public Health 2020, 17, 3459. [CrossRef]

23. Bellini, P.; Checchi, V.; Iani, C.; Bencivenni, D.; Consolo, U. Psychological reactions to COVID-19 and epidemiological aspects of dental practitioners during lockdown in Italy. Minerva Dent. Oral Sci. 2021, 70, 32-43. [CrossRef]

24. Martina, S.; Amato, A.; Rongo, R.; Caggiano, M.; Amato, M. The perception of COVID-19 among Italian dentists: An orthodontic point of view. Int. J. Environ. Res. Public Health 2020, 17, 4384. [CrossRef] [PubMed] 
25. Key, T.; Mathai, N.J.; Venkatesan, A.S.; Farnell, D.; Mohanty, K. Personal protective equipment during the COVID-19 crisis: A snapshot and recommendations from the frontline of a university teaching hospital. Bone Jt. Open 2020, 1, 131-136. [CrossRef]

26. Estrich, C.G.; Mikkelsen, M.; Morrissey, R.; Geisinger, M.L.; Ioannidou, E.; Vujicic, M.; Araujo, M.W. Estimating COVID-19 prevalence and infection control practices among US dentists. J. Am. Dent. Assoc. 2020, 151, 815-824. [CrossRef]

27. Huntley, R.E.; Ludwig, D.C.; Dillon, J.K. Early effects of COVID-19 on oral and maxillofacial surgery residency training-Results from a national survey. J. Oral Maxillofac. Surg. 2020, 78, 1257-1267. [CrossRef] [PubMed]

28. Sah, M.K.; Singh, A.; Sangroula, R.K. Knowledge of novel coronavirus disease (COVID-19) among dental surgeons of Nepal: A nationwide study. BMC Infect. Dis. 2020, 20, 871. [CrossRef] [PubMed]

29. De Stefani, A.; Bruno, G.; Mutinelli, S.; Gracco, A. COVID-19 outbreak perception in Italian dentists. Int. J. Environ. Res. Public Health 2020, 17, 3867. [CrossRef] [PubMed]

30. Sezgin, G.P.; Şirinoğlu Çapan, B. Assessment of dentists' awareness and knowledge levels on the Novel Coronavirus (COVID-19). Braz. Oral Res. 2020, 34. [CrossRef] [PubMed]

31. Arora, S.; Saquib, S.A.; Attar, N.; Pimpale, S.; Zafar, K.S.; Saluja, P.; Abdulla, A.M.; Shamsuddin, S. Evaluation of knowledge and preparedness among indian dentists during the current COVID-19 pandemic: A cross-sectional study. J. Multidiscip. Healthc. 2020, 13, 841. [CrossRef]

32. Putrino, A.; Raso, M.; Magazzino, C.; Galluccio, G. Coronavirus (COVID-19) in Italy: Knowledge, management of patients and clinical experience of Italian dentists during the spread of contagion. BMC Oral Health 2020, 20, 200. [CrossRef]

33. Nasser, Z.; Fares, Y.; Daoud, R.; Abou-Abbas, L. Assessment of knowledge and practice of dentists towards Coronavirus Disease (COVID-19): A cross-sectional survey from Lebanon. BMC Oral Health 2020, 20, 281. [CrossRef]

34. Ahmed, N.; Shakoor, M.; Vohra, F.; Abduljabbar, T.; Mariam, Q.; Rehman, M.A. Knowledge, awareness and practice of health care professionals amid SARS-CoV-2, corona virus disease outbreak. Pak. J. Med Sci. 2020, 36, S49. [CrossRef]

35. Bahramian, H.; Gharib, B.; Baghalian, A. COVID-19 considerations in pediatric dentistry. JDR Clin. Transl. Res. 2020, 5, 307-311. [CrossRef]

36. Cai, X.; Ma, Y.; Li, S.; Chen, Y.; Rong, Z.; Li, W. Clinical characteristics of 5 COVID-19 cases with non-respiratory symptoms as the first manifestation in children. Front. Pediatr. 2020, 8, 258. [CrossRef]

37. Ammar, N.; Aly, N.M.; Folayan, M.O.; Mohebbi, S.Z.; Attia, S.; Howaldt, H.P.; Boettger, S.; Khader, Y.; Maharani, D.A.; Rahardjo, A. Knowledge of dental academics about the COVID-19 pandemic: A multi-country online survey. BMC Med. Educ. 2020, 20, 399. [CrossRef]

38. Khader, Y.; Al Nsour, M.; Al-Batayneh, O.B.; Saadeh, R.; Bashier, H.; Alfaqih, M.; Al-Azzam, S. Dentists' awareness, perception, and attitude regarding COVID-19 and infection control: Cross-sectional study among Jordanian dentists. JMIR Public Health Surveill. 2020, 6, e18798. [CrossRef] [PubMed]

39. Candeiro, G.T.D.M.; Gavini, G.; Vivan, R.R.; Carvalho, B.M.D.F.; Duarte, M.A.H.; FeijÃo, C.P. Knowledge about Coronavirus disease 19 (COVID-19) and its professional repercussions among Brazilian endodontists. Braz. Oral Res. 2020, 34. [CrossRef]

40. Al-Halabi, M.; Salami, A.; Alnuaimi, E.; Kowash, M.; Hussein, I. Assessment of paediatric dental guidelines and caries management alternatives in the post COVID-19 period. A critical review and clinical recommendations. Eur. Arch. Paediatr. Dent. 2020, 21, 543-556. [CrossRef] [PubMed]

41. Dong, Y.; Mo, X.; Hu, Y.; Qi, X.; Jiang, F.; Jiang, Z.; Tong, S. Epidemiology of COVID-19 among children in China. Pediatrics 2020, 145, e20200702. [CrossRef] [PubMed]

42. Bontà, G.; Campus, G.; Cagetti, M.G. COVID-19 pandemic and dental hygienists in Italy: A questionnaire survey. BMC Health Serv. Res. 2020, 20, 994. [CrossRef] [PubMed]

43. Alduraywish, A.A.; Srivastava, K.C.; Shrivastava, D.; Sghaireen, M.G.; Alsharari, A.F.; Al-Johani, K.; Alam, M.K. A countrywide survey in Saudi Arabia regarding the knowledge and attitude of health care professionals about coronavirus disease (COVID-19). Int. J. Environ. Res. Public Health 2020, 17, 7415. [CrossRef]

44. Becker, K.; Brunello, G.; Gurzawska-Comis, K.; Becker, J.; Sivolella, S.; Schwarz, F.; Klinge, B. Dental care during COVID-19 pandemic: Survey of experts' opinion. Clin. Oral Implant. Res. 2020, 31, 1253-1260. [CrossRef] [PubMed]

45. Hakim, M.; Khattak, F.A.; Muhammad, S.; Ismail, M.; Ullah, N.; Atiq Orakzai, M.; Ulislam, S.; Ul-Haq, Z. Access and Use Experience of Personal Protective Equipment Among Frontline Healthcare Workers in Pakistan During the COVID-19 Emergency: A Cross-Sectional Study. Health Secur. 2021, 19, 140-149. [CrossRef] [PubMed]

46. Luzzi, V.; Ierardo, G.; Bossù, M.; Polimeni, A. Paediatric Oral Health during and after the COVID-19 Pandemic. Int. J. Paediatr. Dent. 2021, 31, 20-26. [CrossRef] [PubMed]

47. Esposito, S.; Principi, N. To mask or not to mask children to overcome COVID-19. Eur. J. Pediatr. 2020, 179, 1267-1270. [CrossRef]

48. Tahamtan, A.; Ardebili, A. Real-time RT-PCR in COVID-19 detection: Issues affecting the results. Expert Rev. Mol. Diagn. 2020, 20, 453-454. [CrossRef]

49. Sabino-Silva, R.; Jardim, A.C.G.; Siqueira, W.L. Coronavirus COVID-19 impacts to dentistry and potential salivary diagnosis. Clin. Oral Investig. 2020, 24, 1619-1621. [CrossRef]

50. Quadri, M.F.; Jafer, M.A.; Alqahtani, A.S.; Odabi, N.I.; Daghriri, A.A.; Tadakamadla, S.K. Novel corona virus disease (COVID-19) awareness among the dental interns, dental auxiliaries and dental specialists in Saudi Arabia: A nationwide study. J. Infect. Public Health 2020, 13, 856-864. [CrossRef]

51. Patel, M. Infection control in dentistry during COVID-19 pandemic: What has changed? Heliyon 2020, 6, e05402. [CrossRef] 
52. Melo Neto, C.L.M.; Bannwart, L.C.; de Melo Moreno, A.L.; Goiato, M.C. SARS-CoV-2 and Dentistry-Review. Eur. J. Dent. 2020, 14, S130-S139. [CrossRef] [PubMed]

53. Ather, A.; Patel, B.; Ruparel, N.B.; Diogenes, A.; Hargreaves, K.M. Coronavirus disease 19 (COVID-19): Implications for clinical dental care. J. Endod. 2020, 46, 584-595. [CrossRef]

54. Ates, A.A.; Alomari, T.; Bhardwaj, A.; Tabnjh, A.; Gambarini, G. Differences in endodontic emergency management by endodontists and general dental practitioners in COVID-19 times. Braz. Oral Res. 2020, 34. [CrossRef]

55. Sinjari, B.; Rexhepi, I.; Santilli, M.; Chiacchiaretta, P.; Di Carlo, P.; Caputi, S. The impact of COVID-19 related lockdown on dental practice in Central Italy-outcomes of a survey. Int. J. Environ. Res. Public Health 2020, 17, 5780. [CrossRef] [PubMed]

56. Al-Khalifa, K.S.; AlSheikh, R.; Al-Swuailem, A.S.; Alkhalifa, M.S.; Al-Johani, M.H.; Al-Moumen, S.A.; Almomen, Z.I. Pandemic preparedness of dentists against coronavirus disease: A Saudi Arabian experience. PLoS ONE 2020, 15, e0237630. [CrossRef] [PubMed]

57. Modi, P.D.; Nair, G.; Uppe, A.; Modi, J.; Tuppekar, B.; Gharpure, A.S.; Langade, D. COVID-19 awareness among healthcare students and professionals in Mumbai metropolitan region: A questionnaire-based survey. Cureus 2020, 12, e7514. [CrossRef]

58. Faccini, M.; Ferruzzi, F.; Mori, A.A.; Santin, G.C.; Oliveira, R.C.; de Oliveira, R.C.G.; Queiroz, P.M.; Salmeron, S.; Pini, N.I.P.; Sundfeld, D.; et al. Dental care during COVID-19 outbreak: A web-based survey. Eur. J. Dent. 2020, 14, S14-S19. [CrossRef]

59. Cotrin, P.; Peloso, R.M.; Pini, N.I.P.; Oliveira, R.C.; de Oliveira, R.C.G.; Valarelli, F.P.; Freitas, K.M.S. Urgencies and emergencies in orthodontics during the coronavirus disease 2019 pandemic: Brazilian orthodontists' experience. Am. J. Orthod. Dentofac. Orthop. 2020, 158, 661-667. [CrossRef]

60. Nibali, L.; Ide, M.; Ng, D.; Buontempo, Z.; Clayton, Y.; Asimakopoulou, K. The perceived impact of Covid-19 on periodontal practice in the United Kingdom: A questionnaire study. J. Dent. 2020, 102, 103481. [CrossRef]

61. Ilyas, N.; Agel, M.; Mitchell, J.; Sood, S. COVID-19 pandemic: The first wave-an audit and guidance for paediatric dentistry. Br. Dent. J. 2020, 228, 927-931. [CrossRef]

62. Üstün, N.; Akgöl, B.B.; Bayram, M. Influence of COVID-19 pandemic on paediatric dental attendance. Clin. Oral Investig. 2021, 1-7. [CrossRef]

63. Limbu, S.; Dikshit, P.; Malla, M.; Verma, L.; Khapung, A. Pediatric Dental Emergency Pattern and Dental Care Provided during COVID-19 Pandemic Lockdown at a Tertiary Care Center in Kathmandu, Nepal. J. Nepal Assoc. Pediatr Dent. $2021,2,3-11$.

64. Kumar, G.; Ramos-Gomez, F.; Dhillon, J.K.; Singh, N.; Rehman, F. Pediatric Dental Management in COVID-19 Era: A Contemporary Outlook. J. South. Asian Assoc. Pediatr. Dent. 2021, 4, 34.

65. Chen, X.C.; Ding, J.F.; Xu, D.H.; Cai, Z.G.; Li, X.E.; Shi, Z.D.; Guo, C.B.; Zhou, Y.S. Preventive and control measures for the coronavirus pandemic in clinical dentistry. Chin. J. Dent. Res. 2020, 23, 99-104. [CrossRef]

66. Gallagher, J.E.; Johnson, I.; Verbeek, J.H.; Clarkson, J.E.; Innes, N. Relevance and paucity of evidence: A dental perspective on personal protective equipment during the COVID-19 pandemic. Br. Dent. J. 2020, 229, 121-124. [CrossRef]

67. Sa, Y.; Lin, W.S.; Morton, D.; Huang, C. Coronavirus disease 2019 (COVID-19): Experiences and protocols from the Department of Prosthodontics at the Wuhan University. J. Prosthet. Dent. 2021, 126, 41-50. [CrossRef] [PubMed]

68. Acharya, S.; Singh, B.; Godhi, B.; Pandey, S. How to deal and learn from the threat of COVID-19 in paediatric dentistry. Eur. J. Paediatr. Dent. 2020, 21, 173-175. [CrossRef] [PubMed]

69. Ataş, O.; Yildirim, T.T. Evaluation of knowledge, attitudes, and clinical education of dental students about COVID-19 pandemic PeerJ 2020, 8, e9575. [CrossRef] [PubMed]

70. Falahchai, M.; Babaee Hemmati, Y.; Hasanzade, M. Dental care management during the COVID-19 outbreak. Spec. Care Dent. 2020, 40, 539-548. [CrossRef]

71. Sarfaraz, S.; Shabbir, J.; Mudasser, M.A.; Khurshid, Z.; Al-Quraini, A.A.A.; Abbasi, M.S.; Ratnayake, J.; Zafar, M.S. Knowledge and attitude of dental practitioners related to disinfection during the COVID-19 pandemic. Healthcare 2020, 8, 232. [CrossRef] 